\title{
Biology of Sitophilus oryzae (L.) (Coleoptera: Curculionidae) on Four Different Germplasms of Stored Wheat Grains
}

\author{
Bireshwar Kundu*, Tapan Kumar Hath, Supriya Okram, Debanjan Chakraborty
}

Uttar Banga Krishi Viswavidyalaya, Pundibari, Cooch Behar, West Bengal-736165, India

*Corresponding author

\begin{tabular}{|l|}
\hline Ke y w o r d s \\
Sitophilus oryzae, \\
Developmental \\
stages, Life cycle, \\
Wheat grain, \\
Different \\
germplasms \\
\hline Article Info \\
\hline Accepted: \\
20 May 2018 \\
Available Online: \\
10 June 2018 \\
\hline
\end{tabular}

A B S T R A C T

Laboratory experiments were carried out to study the biology of Sitophilus oryzae on four different wheat germplasms such as (DPW-62150, DBW-39, GW-322, and K-0307). It was found that the different developmental stages of rice weevil were longer during the winter season as compared to the summer season. As lowest incubation period of $3 \pm 0.47$ days was recorded from DPW-62150 while the longest one from DBW-39 with 5.44 \pm 0.42 days. The lowest total larval and pupal period was registered in germplasm DPW-62150 (23 days) while it was highest (34.44 \pm 0.42 days) in DBW-39. Total life cycle of male with food was lowest in GW-322 with $84.10 \pm 0.83$ days while it was highest with $95.43 \pm 0.80$ days in DBW-39; similarly for female with food the lowest and longest of life cycle was noted on the same germplasm with $110 \pm 0.82$ days and $123.10 \pm 0.83$ days respectively. When the male and female adults were devoid of food, the life cycle of male and female was lowest on DPW-62150 and highest on DBW-39 with $40.00 \pm 0.82$ days and $44.33 \pm 0.94$ days and $53.43 \pm 0.61$ days and $60.43 \pm 0.8$ days respectively during summer and that of winter with incubation period of $7.67 \pm 0.47$ days in DPW-62150 to $11.00 \pm 0.82$ days in DBW-39. Total larval and pupal period varied from $34.67 \pm 0.47$ days to $42.33 \pm 0.47$ days in DPW-62150 and K-0307 respectively. Total life cycle of male with food ranged from $104 \pm 0.94$ days (DPW-62150) to $110.33 \pm 0.94$ days (DBW-39) while for the female the range was form $128.00 \pm 0.82$ days $(\mathrm{GW}-322)$ to $137.33 \pm 1.25$ days $(\mathrm{K}-0307)$. On the other hand total life cycle of the male devoid of food to adult, ranged from $56 \pm 0.82$ days to $66.67 \pm 0.94$ days while the same for female was from $60.33 \pm 0.47$ days to $73.67 \pm 0.94$ days

\section{Introduction}

Wheat (Triticum aestivum L.) is the most important staple food for human and is grown on more land than any other commercial crops in the world. Approximately $1 / 6^{\text {th }}$ of the total arable land in the world is under wheat cultivation (Slafer and Satorre, 1999). It is the most important staple food of about two billion people $(36 \%$ of the world's population).Worldwide, wheat provides nearly $55 \%$ of the carbohydrates and $20 \%$ of the food calories consumed globally (Breiman and Graur, 1995). Wheat has higher protein content than either maize or rice or any other cereals and related to human food globally. Increased wheat demand is driven by a rapidly growing population and a change in food 
preference away from traditional cereals and towards wheat and wheat products (World Bank, 1989). Wheat occupies an important place in the economy of our country (Chowdhury et al., 1998). The intensification of food production has led to several problems in the post-harvest phase including the major concern of pest infestation during storage (Khalequzzaman and Khanom, 2006). Every year about $25-30 \%$ crop yields are damaged in field and stores by different insect pests (Lal and Srivastava, 1996). Although wheat has only few insect-pests under field conditions, but it is susceptible to storage pests which cause substantial qualitative / nutritional and quantitative losses of various magnitudes depending on the pest species and duration of storage (De Lima, 1979; Sighamony et al.,1985). Deterioration of storage grain is influenced by physical (temperature, humidity), biological (micro flora, arthropod, vertebrates) and technical (storage conditions, methods and duration) factors and the most damaging species of storage insect are in the genera Sitophilus and Tribolium (Marsans, 1987; Khan and Suleman, 1988; Pinto et al., 1997). Among the various insect pests rice weevil, Sitophilus oryzae (L.) is the most destructive pest of stored grains in wheat (Cotton, 1920). It is originated in India and distributed worldwide (Cotton, 1920). It causes $18.30 \%$ losses to stored grain (Adams, 1976). This species has a relatively short developmental period and high populations can easily build up (Aitken, 1975). S. oryzae is small and stout in appearance with reddish brown to black in colour. The adult gathers and reproduces in stored grains. Female weevil may bore at several parts of grain but only one egg is laid down in a single grain and seals the hole with gelatinous fluid. The grub feed inside the grain kernels for an average of 18 to 34 days. A larva of Sitophilus oryzae consumes $14 \mathrm{mg}$ grain / day (Giolebiowska, 1968). They feed on its starchy content and hallowing it out leaves the shell intact. The two sexes of Sitophilus oryzae look apparently alike but when carefully examined the male can be distinguished from female by the form of rostrum which is shorter in male than in female. It has been reported to fly towards wind direction (Khare and Agrawal, 1970). In West Bengal total 960 tonne wheat was produced in 340 hectare of land during (20152016). Productivity of wheat was $2825 \mathrm{~kg} / \mathrm{ha}$. during (2015-2016). Wheat is an important crop in West Bengal. In North Bengal condition wheat is considered as a main winter crop in the cropping system followed by a vast majority of the farmers. Procement and storage of wheat is done by private and government agencies to meet the food requirement of the population round the year. After the harvest of the crop, the stored grains are subjected to insect attack, causing considerable loss. For management of pests we still rely on pesticides.

Keeping the above facts in view, investigations were carried out with the study of the life history, habits and habitats which are necessary to have thorough understanding of the situation favourable to the pest which should be taken advantage for the effective management of the pest.

\section{Materials and Methods}

Biology of the rice weevil, Sitophilus oryzae was carried out on four different wheat germplasms such as DPW-62150, DBW-39, GW-322 and K-0307 under laboratory condition during July to September, 2016 and December to February 2016-2017 at Department of Agricultural Entomology, UBKV, Pundibari. Stock culture of the rice weevil was initiated by collecting the adult weevils from the infested wheat grains from university farm store house. The culture was further maintained in glass jars (of two litre capacity) containing the wheat grains. The mouth of the container was covered with a 
muslin cloth. Newly hatched adults were identified based on their rostra following Halstead (1963). After the identification ten pairs of rice weevils were released in $50 \mathrm{~g}$ wheat grains in each plastic jar of $250 \mathrm{gm}$ capacity with three replications in each bottle and these bottles were kept in ambient conditions. The experiment was designed in CRD with three replications. Fresh grains were provided periodically for the development of beetles. Damaged grains were removed every morning from the bottles. Grains containing eggs were separated out by examining under binocular and were used for further studies. Five grains from each of the varieties, obtained so, were maintained in glass-vials (one grain in each vial) for incubation. The grains were examined properly by taking out from the vials and dissected the accordingly to determine the incubation period. Larval instars were determined by the presence of moulted skin and range of head capsule width as described by (Sharifi and Mills, 1971). Pupal period was determined by subtracting incubation and larval period from the total period of egg laying to the adult emergence. The ability of the adults of $S$. oryzae to live in the presence or absence of food was determined by enclosing the male and female adults obtained from the culture separately. Three such vials were maintained for each of the varieties. In the $1^{\text {st }}$ vial one male was released with food (wheat grains), in $2^{\text {nd }}$ vial one female was released with food and in the $3^{\text {rd }}$ one a pair of adults were released without food. The same procedures were followed in both the seasons.

\section{Results and Discussion}

A perusal data contained in Table 1 revealed that during summer season the lowest incubation period of $3 \pm 0.47$ days was recorded from DPW-62150 while the longest one from DBW-39 with 5.44 \pm 0.42 days. The lowest total larval and pupal period was registered in germplasm DPW-62150 (23 days) while it was highest (34.44 \pm 0.42 days) in DBW-39. Male and female adults supported with food survived the longest duration of $60.33 \pm 0.47$ and $90.67 \pm 0.94$ days respectively on DPW-62150 which was followed by K0307 (56.00 \pm 0.82 and $85.67 \pm 0.94$ days), DBW-39 (55.67 \pm 0.94 and $83.33 \pm 0.47$ days) and $\mathrm{GW}-322(55.00 \pm 0.0$ and $81.00 \pm 0.82$ days respectively). When devoid of food, the adult male survived for the lowest duration in DPW-62150 (13.67 \pm 0.47 days) while the

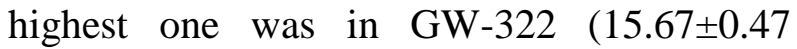
days); similarly for adult female, the lowest longevity was recorded in K-0307 (17.67 \pm 0.47 days) while the highest one was DBW-39 (20.67 \pm 0.94$)$.

Total life cycle of male with food was lowest

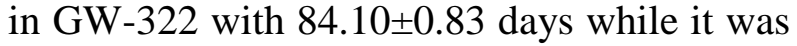
longest with $95.43 \pm 0.80$ days in DBW-39; similarly for female with food the lowest and longest duration of life cycle was noted on the same germplasm with $110 \pm 0.82$ days and $123.10 \pm 0.83$ days respectively. When the male and female adults were devoid of food, the life cycle of male and female was lowest on DPW62150 and highest on DBW-39 with $40.00 \pm 0.82$ days and $44.33 \pm 0.94$ days and $53.43 \pm 0.61$ days and $60.43 \pm 0.8$ days respectively.

A perusal data contained in Table 2 revealed that during winter season the duration of different stages was longer in winter season than that of summer months. Incubation period ranged from $7.67 \pm 0.47$ days in DPW62150 to $11.00 \pm 0.82$ days in DBW-39. Total larval and pupal period varied from $34.67 \pm 0.47$ days to $42.33 \pm 0.47$ days in DPW62150 and K-0307 respectively. Adult male without food survived for a minimum of $13.67 \pm 0.47$ days in DPW-62150 and the maximum of $15.67 \pm 0.47$ days in GW322. Adult female without food survived for a minimum and maximum period of $17.67 \pm 0.47$ 
days and 20.67 \pm 0.94 days in K-0307 and DBW-39 respectively. It was observed that with food the adult male longevity ranged from $56.00 \pm 0.82$ days to $62.32 \pm 0.47$ days in K-0307 and DPW-62150 respectively. There was no variation in the female adult longevity with food in winter in all the four germplasms and the result were identical to that of summer season. Total life cycle of male with food ranged from $104 \pm 0.94$ days (DPW-62150) to $110.33 \pm 0.94$ days (DBW-39) while for the female the range was form $128.00 \pm 0.82$ days $(\mathrm{GW}-322)$ to $137.33 \pm 1.25$ days $(\mathrm{K}-0307)$. On the other hand total life cycle of the male devoid of food, ranged from $56 \pm 0.82$ days to $66.67 \pm 0.94$ days while the same for female varied from $60.33 \pm 0.47$ days to $73.67 \pm 0.94$ days.

Table.1 Biology of Sitophilus oryzae on four different wheat germplasms under laboratory condition during summer season

\begin{tabular}{|l|l|l|l|l|l|}
\hline SI. & \multicolumn{1}{|c|}{ Parameters } & Duration (days) in four different wheat germplasms \\
\cline { 3 - 5 } & & DPW62150 & K-0307 & DBW-39 & GW-322 \\
\hline $\mathbf{1}$ & Incubation period & $3 \pm 0.47$ & $4.33 \pm 0.27$ & $5.44 \pm 0.42$ & $4.00 \pm 0.27$ \\
\hline $\mathbf{2}$ & Total larval and pupal period & 23 & $27.44 \pm 0.79$ & $34.44 \pm 0.42$ & $25.11 \pm 0.57$ \\
\hline $\mathbf{3}$ & Adult longevity of male with food & $60.33 \pm 0.47$ & $56.00 \pm 0.82$ & $55.67 \pm 0.94$ & $55.00 \pm 0.00$ \\
\hline $\mathbf{4}$ & adult longevity of female with food & $90.67 \pm 0.94$ & $85.67 \pm 0.94$ & $83.33 \pm 0.47$ & $81.00 \pm 0.82$ \\
\hline $\mathbf{5}$ & Adult longevity of male without food & $13.67 \pm 0.47$ & $14.33 \pm 0.94$ & $13.67 \pm 1.25$ & $15.67 \pm 0.47$ \\
\hline $\mathbf{6}$ & $\begin{array}{l}\text { Adult longevity of female without } \\
\text { food }\end{array}$ & $18.00 \pm 0.82$ & $17.67 \pm 0.47$ & $20.67 \pm 0.94$ & $19.67 \pm 0.47$ \\
\hline $\mathbf{7}$ & Total life cycle of male with food & $86.67 \pm 0.47$ & $87.87 \pm 1.14$ & $95.43 \pm 0.8$ & $84.10 \pm 0.83$ \\
\hline $\mathbf{8}$ & Total life cycle of female with food & $117.00 \pm 0.82$ & $117.43 \pm 1.8$ & $123.10 \pm 0.83$ & $110 \pm 0.82$ \\
\hline $\mathbf{9}$ & Total life cycle of male without food & $40.00 \pm 0.82$ & $46.10 \pm 1.13$ & $53.43 \pm 0.61$ & $44.47 \pm 1.28$ \\
\hline $\mathbf{1 0}$ & Total life cycle of female without food & $44.33 \pm 0.94$ & $49.43 \pm 1.52$ & $60.43 \pm 0.8$ & $48.77 \pm 0.56$ \\
\hline
\end{tabular}

Table.2 Biology of Sitophilus oryzae on four different wheat germplasms under laboratory condition during winter season

\begin{tabular}{|c|c|c|c|c|c|}
\hline \multirow{2}{*}{$\begin{array}{l}\text { Sl. } \\
\text { No }\end{array}$} & \multirow{2}{*}{ Parameters } & \multicolumn{4}{|c|}{ Duration (days) in four different wheat germplasms } \\
\hline & & DPW62150 & K-0307 & DBW-39 & GW-322 \\
\hline 1 & Incubation period & $7.67 \pm 0.47$ & $9.33 \pm 0.47$ & $11.00 \pm 0.82$ & $8.33 \pm 0.47$ \\
\hline 2 & Total larval and pupal period & $34.67 \pm 0.47$ & $42.33 \pm 0.47$ & $42.00 \pm 0.82$ & $38.67 \pm 0.47$ \\
\hline 3 & Adult longevity of male with food & $62.32 \pm 0.47$ & $56.00 \pm 0.82$ & $56.67 \pm 0.47$ & $58.33 \pm 0.47$ \\
\hline 4 & adult longevity of female with food & $90.67 \pm 0.94$ & $85.67 \pm 0.94$ & $83.33 \pm 0.47$ & $81.00 \pm 0.82$ \\
\hline 5 & Adult longevity of male without food & $13.67 \pm 0.47$ & $14.33 \pm 0.94$ & $13.67 \pm 1.25$ & $15.67 \pm 0.47$ \\
\hline 6 & Adult longevity of female without food & $18.00 \pm 0.82$ & $17.67 \pm 0.47$ & $20.67 \pm 0.94$ & $19.67 \pm 0.47$ \\
\hline 7 & Total life cycle of male with food & $104 \pm 0.94$ & $110.33 \pm 0.94$ & $110.00 \pm 1.41$ & $105.33 \pm 1.25$ \\
\hline 8 & Total life cycle of female with food & $133 \pm 0.82$ & $137.33 \pm 1.25$ & $137.33 \pm 0.83$ & $128.00 \pm 0.82$ \\
\hline 9 & Total life cycle of male without food & $56.00 \pm 0.82$ & $66.00 \pm 0.82$ & $66.67 \pm 0.94$ & $62.67 \pm 1.25$ \\
\hline 10 & Total life cycle of female without food & $60.33 \pm 0.47$ & $69.33 \pm 0.94$ & $73.67 \pm 0.47$ & $66.67 \pm 0.47$ \\
\hline
\end{tabular}


It was summarized that incubation varied among the germplasms. Lowest incubation period of $3 \pm 0.47$ days was recorded from DPW-62150 while the longest one from DBW-39 with 5.44 \pm 0.42 days. The lowest total larval and pupal period was registered in germplasm DPW-62150 (23 days) while it was highest $(34.44 \pm 0.42$ days $)$ in $\mathrm{DBW}-39$. Total life cycle of male with food was lowest in GW-322 with $84.10 \pm 0.83$ days while it was highest with $95.43 \pm 0.80$ days in DBW-39; similarly for female with food the lowest and longest of life cycle was noted on the same germplasm with $110 \pm 0.82$ days and $123.10 \pm 0.83$ days respectively. When the male and female adults were devoid of food, the life cycle of male and female was lowest on DPW-62150 and highest on DBW-39 with $40.00 \pm 0.82$ days and $44.33 \pm 0.94$ days and $53.43 \pm 0.61$ days and $60.43 \pm 0.8$ days respectively. The duration of different stages was longer in winter season than summer month's incubation period ranged from $7.67 \pm 0.47$ days in DPW-62150 to $11.00 \pm 0.82$ days in DBW-39. Total larval and pupal period varied from $34.67 \pm 0.47$ days to $42.33 \pm 0.47$ days in DPW-62150 and K-0307 respectively. Total life cycle of male with food ranged from $104 \pm 0.94$ days (DPW62150 ) to $110.33 \pm 0.94$ days (DBW-39) while for the female the range was form $128.00 \pm 0.82$ days $(\mathrm{GW}-322)$ to $137.33 \pm 1.25$ days (K-0307). On the other hand total life cycle of the male devoid of food to adult, ranged from $56 \pm 0.82$ days to $66.67 \pm 0.94$ days while the same for female was from $60.33 \pm 0.47$ days to $73.67 \pm 0.94$ days.

\section{References}

Adams, J. M. (1976). Weight loss caused by development of S. oryzae. J. Stor. Prod. Res. 12: 269-272.

Aitken, A. D. (1975). Insect travelers I: Coleopteran Technical Bulletin HMSO, London, United Kingdom. p31.

Breiman, A. and Graur, D. (1995). Wheat
Evaluation. Israel Journal Plant Science. 43: 58-95.

Chowdhry, M. A., Maqbool, A., Mahmood, N. and Khaliq, I. (1998). Performance of pure and mixed stands for biomass and grain yield in Hexaploid wheat. Pak. J. Biol. Sci. 1:145-147.

Cotton, R. T. (1920). Rice weevil, Sitophilus oryzae (L.) Journal of Agricultural Research. 20: 409.

De Lima, C. P. F. (1979). The assessment of losses due to insects and rodents in maize stored for subsistence in Kenya. Tropical Products Information. 38: 2126.

Giolebiowska, Z. (1968). The feeding and fecundity of Sitophilus granaries (L), Sitophilus oryzae (L) and Rhizopertha dominica $(\mathrm{F})$ in wheat grain. Journal of Stored Products Research. 5: 143-155.

Halstead, D. G. H., 1963. External sex difference in store product coleoptera. Bulletin of Entomological Research, 54: 119-134.

Khalequzzaman, M and Khanomi, M. (2006). Effect of cypermethrin alone and in combination with leaf and seed extract of neem against adult Tribolium castaneum (Herbest). Rajshahi University Journal of Zoology. 25: 4549.

Khan, A. R. and Selman, B. J. (1988). On the mortality of Tribolium castaneum adults treated sub lethally as larvae with pirimiphos methyl, Nosemawhitei and pirimiphos methyl-N. white doses. Entomophaga. 33: 377-380.

Khare, B. P. and Agrawal, N. S. (1970).Studies on biology of Sitophilus oryzae (Linn) and their distinguishing character in male and female. Journal of Stored Product Research. 20: 183-188.

Lal, S. and Shrivastava, B. P. (1996). Insect pest of stored wheat in Madhya Pradesh (India). Journal of Entomological Research. 9 (2): 141-148. 
Marsans, G. (1987). Manejo y Conservaciô̂ $\mathrm{n}$ de Granos. Ed. Hemisferio Sur, Buenos Aires, p. 266.

Pinto Jr, A. R., Furiatti, R. S., Pereira, P. V. S. and Lazzari, F. A. (1997). Avaliacao de Insecticidas no Controle de Sitophilus oryzae (L.) (Coleoptera: Curculionidae), e Rhyzopertha dominica (Fab.) (Coleoptera: Bostrichidae) em Arroz Armazenado. Anais da Sociedade Entomologica, do Brasil. 26: 285-290.

Sharifi, S. and Mills, R. B. (1971). Radiographic studies of Sitophilus zemais (Motsh.) in wheat kernels. $J$. Econ. Entomol., 7: 105-106.

Singhamony, S., Anees, I., Chandrakala, T. and Osman, Z. (1985). Efficacy of certain indigenous plants products as grain protectants against $S$. oryzae (L) and $R$. dominica (F). Journal of Stored Products Research. 22 (10): 21-23.

Slafer, G. A. and Satorre, E. H. (1999). An introduction to the physiologicalecological analysis of wheat yield In Wheat - Ecology and physiology of yield determination. Food Products Press, Binghamton, NY, USA.

World Bank. (1989). Kenya Agricultural Growth and Strategy Options. Unpublished Sector Report, Nairobi, Kenya: The World Bank.

\section{How to cite this article:}

Bireshwar Kundu, Tapan Kumar Hath, Supriya Okram, Debanjan Chakraborty. 2018. Biology of Sitophilus oryzae (L.) (Coleoptera: Curculionidae) on Four Different Germplasms of Stored Wheat Grains. Int.J.Curr.Microbiol.App.Sci. 7(06): 2401-2406. .doi: https://doi.org/10.20546/ijcmas.2018.706.285 